The Effect of Victim Intoxication and Crime Type on

Mock Jury Decision-Making

Authors:

ERICA MARTIN, LAUREN A. MONDS ${ }^{1}$

${ }^{1}$ Discipline of Addiction Medicine, University of Sydney, Sydney, Australia

Corresponding Author:

Erica Martin

emar5644@uni.sydney.edu.au

Word Count: 6081 


\begin{abstract}
Alcohol intoxication is a common feature in crime, yet jurors often possess little understanding of how alcohol affects eyewitness memory. Furthermore, jurors are often blind to biases about different crimes that affect their interpretation of eyewitness evidence. Accordingly, the current study investigated the impact of (1) a victim's intoxication status during a crime and (2) the type of crime committed on mock jury decision-making. Undergraduate students $(N=228)$ read a trial transcript describing a rape or robbery committed against a woman who was either sober or intoxicated to a low, moderate, or severe degree when the crime occurred. They also completed questionnaires assessing trial-related judgements, alcohol beliefs, behaviours and familiarity, and sexist attitudes towards women. Mock jurors incorrectly perceived alcohol as detrimental to the victim's credibility at any dose. However, the victim's intoxication status failed to influence verdict decisions. Verdicts were instead better accounted for by extra-legal factors such as gender, ethnicity, and alcohol-related beliefs. Variance in jury decision-making according to crime type was not observed. These null findings may be the product of methodological constraints rather than genuine non-effects, and thus further research is required. The current study asserts the need for jury education to correct misconceptions about the effects of alcohol on eyewitness memory, and continued exploration of the role of extra-legal factors in intoxication-related cases.
\end{abstract}

Keywords: alcohol, intoxication, jury decision-making, sexual assault 


\section{The Effect of Victim Intoxication and Crime Type on Mock Jury Decision-Making}

Alcohol intoxication is common among witnesses, victims, and perpetrators of crime (Flowe et al., 2019). The association between alcohol and criminality is especially pronounced in serious crimes such as homicide and sexual assault: up to $78 \%$ of perpetrators and $72 \%$ of victims are intoxicated when these crimes occur (Kloft et al., 2021). As jurors frequently evaluate testimony about crimes involving alcohol, it is essential to understand how the following factors affect jurors' evaluations of eyewitness evidence:

1. The intoxication status during a crime of a victim providing testimony at trial; and 2. The type of crime committed.

Mock jurors have historically perceived alcohol intoxication as detrimental to eyewitness memory and a barrier to positive evaluation, especially of rape victims (Monds et al., 2021; Lynch et al., 2013). Therefore, the present study may reveal intoxicated rape victims as possessing exceptional procedural vulnerabilities that must be addressed.

\section{Jurors' Evaluation of Alcohol Intoxication and Eyewitness Testimony}

\section{The Effect of Alcohol Intoxication on Eyewitness Memory}

Survey research has revealed a popular belief that alcohol impairs the credibility of eyewitness testimony. For example, Benton et al. (2006) established that at least $90 \%$ of jurors, judges, and police officers perceived alcohol as detrimental to eyewitness memory. The extreme uniformity of these beliefs warrants concern; if they are false, jurors may reach incorrect verdicts based on unfair dismissal of accurate testimony.

Experimental research has challenged the expectation that alcohol necessarily produces poorer recall by testing memory for crimes. A meta-analysis by Jores et al. (2019) established that intoxicated individuals provide less detailed testimony, but the details they do recall are no less accurate than their sober counterparts'. This effect is overpowered only 
when alcohol consumption is significant (i.e., BAC > .08\%; Altman et al., 2018). Thus, although alcohol does impair memory, the impairment is much less ubiquitous than expected.

When considered alongside the standard belief that alcohol inevitably damages memory, this research suggests that there is a discrepancy between how jurors expect alcohol to affect memory and how it actually does (Benton et al., 2006). Therefore, jury-focused research is required to understand the extent to which individuals inappropriately disregard the testimony of intoxicated victims.

\section{Jurors' Perception of Intoxication-Related Testimony}

Most of the jury-focused literature contends that jurors perceive witnesses who were intoxicated during a crime to be less credible compared to witnesses who were sober (Evans \& Schreiber Compo, 2010; Monds et al., 2021). This negative impression of intoxicationrelated testimony is associated with a reduced likelihood of conviction (Schuller \& Wall, 2006). However, studies exploring the unique contribution of different levels of intoxication to assessments of credibility are scarce and results are somewhat uninformative. Evans and Schreiber Compo (2010) found that while participants were sensitive to an overall negative impact of alcohol on the credibility of line-up identifications, they did not distinguish between different levels of intoxication. Crossland et al. (2021) failed to detect an effect of intoxication level on evaluations of a specific trial witness, but observed a general belief that credibility deteriorates with increasing inebriation.

These studies employed only three intoxication conditions: sober, moderate, and severe. Given past failures to detect a difference between moderate and severe intoxication, the present study includes a low intoxication condition. This will clarify the level at which alcohol is perceived to become detrimental to memory, or whether merely its presence - even at a low level - is enough to discredit a victim's testimony. 


\section{The Role of Individual Differences}

The Australian criminal justice system lacks an objective and consistently applied definition of intoxication (Quilter \& McNamara, 2018). Instead, inexact, colloquial language is used, discretionary assessments are common, and the effects of alcohol are considered lay rather than expert knowledge. Consequently, jurors are often burdened with the task of deciding whether an individual's intoxicated state is relevant to their testimony. It is therefore essential to understand whether jurors' own drinking beliefs and behaviours affect their judgements.

Experimental results have been mixed. Crossland et al. (2021) observed that alcohol beliefs were negatively related to credibility when the victim was moderately - but not severely - intoxicated. Furthermore, while Zhu et al. (2022) found that lower personal alcohol consumption predicted lower ratings of victim credibility, this finding held regardless of whether the victim was intoxicated or sober. Given these inconsistent results, a secondary aim of the present study is to clarify the role of individual differences to alcohol-related jury decision-making. Findings may inform the voir dire process, during which jurors can be dismissed as a threat to impartiality (Horan \& Goodman-Delahunty, 2010).

\section{Jurors' Decision-Making Across Crime Types}

Victims of different crimes are viewed inconsistently by jurors. Bieneck and Krahé (2011) and Spille (2015) observed more blame directed towards sexual assault victims compared to robbery victims. They suggest that victims who violate schematic expectations about appropriate victim behaviour are judged more harshly. While robbery schemas exist, they focus almost exclusively on the perpetrator's behaviour (Holst \& Pezdek, 1992). In contrast, victim-focused and culturally pervasive rape myths increase the likelihood that an individual will be accused of schema violations following a sexual assault. This distinction was demonstrated by Bieneck \& Krahé (2011): victim blame attributions were affected by 
contextual information in a robbery case, but were significantly influenced by the victim's intoxication status and relationship with the perpetrator in a rape case.

Both Bieneck and Krahé (2011) and Spille (2015) compared very different scenarios, and therefore their conclusions must be interpreted cautiously. Uncontrolled variables (e.g., victim description, presence of a weapon) may have contributed to results. Furthermore, both studies employed a vignette methodology, which has been criticised as too crude and unrealistic to capture ecologically valid jury decision-making (O’Dell, 2012). The current study uses a trial transcript that remains identical across conditions - excluding independent variable manipulations - to clarify these findings while improving experimental and ecological validity.

\section{Crime Schemas and their Role in Jury Decision-Making}

Jury decision-making may be shaped by culturally informed attitudes towards sexual assault known as rape myths. These "prejudicial, stereotypical, or false beliefs about rape" include denials of severity and scope, and beliefs that exonerate perpetrators and blame victims (Burt, 1980, p. 217; McMahon \& Farmer, 2011). Sexism predicts rape myth acceptance but remains conceptually distinct (Suarez \& Gadalla, 2010). Therefore, the current study measures sexism to explore schematic evaluations of crime actors while avoiding theoretical exclusivity to rape.

To date, only one study has explored the contribution of sexism to jury decisionmaking across different crimes. Felson \& Palmore (2021) observed that those who endorsed traditional gender roles judged rape victims more harshly, but were no more likely to blame victims of physical assault, robbery, or homicide that those with liberal gender attitudes. This suggests that despite the conceptual separation between sexism and rape, the relationship between sexism and victim appraisal may be unique to sexual assault. This study focused on the victim's culpability rather than credibility; a crucial distinction highlighting the difference 
between responsibility and the capacity to recall an event accurately and truthfully. By focusing on credibility judgements and verdicts, the current study extends this literature beyond abstract blame attributions to concrete legal outcomes.

\section{The Interaction Between Victim Intoxication Status and Crime Schemas}

Alcohol use can inform schema-driven judgements, as drunkenness is judged more negatively in women than men (Blume, 1986). This double standard is driven by a discrepancy between expectations about female conduct and reality: traditional beliefs about women as pure encourage derogation of these who breach these expectations (Bogren, 2008).

Intoxication plays an especially important role in assessments of sexual assault. Rape victims who were intoxicated during the event are blamed more for their victimisation, viewed as less credible, and are less likely to see their assailant convicted (Lynch et al., 2013). Finch \& Munro (2007) suggest these effects are the result of jurors' fixation on intoxicated rape victims' behaviour and their belief that intoxicated women are promiscuous and responsible for all outcomes.

Despite a substantial rape-focused literature, few studies have investigated how intoxication affects judgements of victim credibility across different crimes. Bieneck and Krahé (2011) found that although a victim's intoxication status did not affect mock jurors' judgements of her accountability in a robbery case, she was blamed significantly more when intoxicated during a rape. Alternatively, Spille (2015) observed that victims of both rape and robbery were blamed when intoxicated. The utility of these studies is limited by their binary use of intoxication: the victim was only either 'sober' or 'drunk'. Furthermore, these studies again focused on victim culpability rather than credibility. A jury's belief that a victim is responsible for an altercation is separate from their judgement of whether the defendant committed a crime. Thus, the current study aims to resolve and extend the current findings while considering a broader spectrum of intoxication. 


\section{The Current Study}

The present study examines the influence of victim intoxication status and crime type on jury decision-making. A focus on the interaction between these variables was selected to integrate research exploring jurors' misunderstanding of the effects of alcohol on memory, and their engagement with alcohol as a derogation enhancing variable across different crimes. Furthermore, the present study aims to determine whether victim intoxication status and crime type are primary contributors to jury decision-making, or whether extra-legal variables (e.g., sexism, personal alcohol consumption) better account for trial outcomes.

The current study is the first to assess credibility judgements of a victim with a low intoxication status during the crime, and thus is the most comprehensive investigation of alcohol and jury decision-making to date. Since extraneous differences between crime scenarios represent a common weakness of crime type research, the current study ensures the consistency of case details across conditions. Finally, trial transcripts are used over vignettes to obtain realistic, forensically relevant insights into jury decision-making.

\section{Hypotheses}

\section{Primary Aims.}

H1: As victim intoxication increases, jurors will (a) perceive the victim's testimony as less credible, (b) be less likely to deliver a guilty verdict, and (c) consider the defendant less responsible and the victim more responsible.

H2: Jurors in a sexual assault case will (a) perceive the victim's testimony as less credible, (b) be less likely to deliver a guilty verdict, and (c) consider the defendant less responsible and the victim more responsible, compared to those in a robbery case.

H3: Intoxication and crime type will interact such that the negative effects of intoxication on jury decision-making will be more pronounced in the sexual assault case compared to the robbery case. 
Secondary Aims. The influence of personal alcohol consumption, drinking beliefs, sexist attitudes towards women, and gender on jury decision-making will be investigated as secondary study aims. As these aims - and the contribution of these variables relative to victim intoxication status and crime type - are exploratory, no directional hypotheses were made.

\section{Method}

\section{Participants}

228 undergraduate psychology students completed the study in exchange for course credit. Participants were required to be at least 18 years of age and fluent in English based on Australian jury eligibility.

\section{Design}

The study employed a 4 (victim intoxication status: sober, low, moderate, severe) x 2 (crime type: rape, robbery) between-subjects design. The dependent variables were verdict, perceived credibility of the victim, and perceived responsibility of the victim and defendant. To assess the relative importance of victim intoxication status and crime type to jury decision-making, extra-legal factors such as participants' alcohol consumption, drinking beliefs, attitudes towards women, and demographic factors (e.g., gender) were also explored as predictors of dependent variables.

\section{Stimulus Materials}

\section{Trial Transcript}

The transcript was comprised of introductory and concluding judicial instructions, and victim testimony was adapted from the sexual assault scenario of Bieneck \& Krahé (2011). The testimony was given by a woman who was attacked by a male stranger while walking home from dinner. Eight transcripts were developed to reflect experimental manipulations. 


\section{Crime Type Manipulation}

Half the sample $(n=114)$ read a transcript describing a robbery, while the remaining half $(n=114)$ read about a sexual assault. In the robbery condition, the perpetrator demanded that the victim give him her jewellery and wallet. In the rape condition, the perpetrator restrained the victim and sexually assaulted her. The transcripts were identical across crime type conditions in all other respects.

\section{Victim Intoxication Manipulation}

Participants were randomly assigned to one of four intoxication conditions (see Table 1). The number of drinks in the sober, moderate, and severe conditions were modelled from Evans and Schreiber Compo (2010). As low intoxication was not included in previous studies, Australian drinking guidelines informed this condition (National Road Safety Partnership Program, 2017).

\section{Table 1}

Communication of the Victim's Intoxication Status Across Intoxication Conditions

\begin{tabular}{cccc}
\hline Condition & Drinks Consumed & Degree of Stumbling & Description \\
\hline Sober & 4 lemonades & None & None \\
Low & 2 beers & None & 'Only a little bit \\
Moderate & 4 beers & 'A bit' & intoxicated' \\
Severe & 10 beers & 'A lot' & 'Soderately intoxicated' \\
\hline
\end{tabular}


Measures

Demographic Questionnaire

Participants reported their age, gender, ethnicity, first/preferred language, and Australian citizenship status.

\section{Drinking Beliefs}

Five items measured beliefs about alcohol consumption. The first two were adapted from Evans and Schreiber Compo (2010) and assessed agreement with statements about the irresponsibility of drinking and its impact on decision-making (e.g., 'People make bad decisions when they drink'). Responses were delivered on a 5-point Likert scale $(1=$ strongly disagree, $5=$ strongly agree $)$, where higher scores indicate greater agreement. The third item was adapted from the Revised Version of the Updated Illinois Rape Myth Acceptance Scale (rIRMA; Fejervary, 2017). It captured perceptions of the culpability of an intoxicated victim according to crime type condition (e.g., 'If a person is robbed while they are drunk, then they are at least somewhat responsible for making themselves vulnerable'). Responses were delivered on the same Likert scale as above. The final two items were adapted from Monds et al. (2021). Participants rated the degree to which alcohol negative impacts memory on a 5point Likert scale $(1=$ not at all, $5=$ extremely $)$, where higher scores indicate stronger endorsement. They then responded to a multiple-choice question asking whether an intoxicated victim is more, less, or equally credible compared to a sober victim.

\section{Ambivalent Sexism Inventory - Short Form (ASI)}

The ASI (Glick \& Whitehead, 2010) measures sexist attitudes towards women along two dimensions: hostile and benevolent sexism. Hostile sexism antagonistically positions women as a threat to male dominance, while benevolent sexism idealises women as pure and worthy of protection yet also weak and subordinate (Glick \& Fiske, 1996). Participated rated their agreement with twelve statements on a 6 -point Likert scale $(0=$ strongly disagree, $5=$ 
strongly agree). Six statements reflected hostile sexism, while the remaining six reflected benevolent sexism. Higher scores indicate stronger sexist attitudes towards women.

\section{Perceptions of Police Scale (POPS)}

The POPS (Nadal \& Davidoff, 2015) measures perceptions of police and police bias. Participants rated their agreement with twelve statements on a 5-point Likert scale $(1=$ strongly agree, 5 = strongly disagree), where higher scores indicate less favourable perceptions of police. The POPS was included as a distractor task to conceal the purpose of the study.

\section{Verdict}

Verdict was measured in two ways: dichotomously (i.e., 'guilty' or 'not guilty') and a rating of the probability that the defendant committed the crime. The rating was delivered on a 7-point Likert scale $(1=$ low probability, 7 = high probability), with higher scores indicating stronger belief in defendant guilt. This two-step assessment was used to obtain ecologically valid data and a more nuanced understanding of the extent of perceived guilt precluded by a binary measure (e.g., Cullen et al., 2020).

\section{Perceived Victim Credibility}

The credibility of the victim as a witness was assessed using a seven-item measure adapted from Berman \& Cutler (1996). Ratings were delivered on a 7-point Likert scale $(1=$ not at all, $7=$ very), with higher scores indicating greater perceived credibility.

\section{Perceived Responsibility}

The perceived responsibility of the perpetrator for the incident was assessed via agreement with a single item on a 7-point Likert scale $(1=$ not at all, $7=$ very $m u c h)$. Higher scores indicate greater perceived responsibility. This item was replicated to measure perceptions of the victim's responsibility. 


\section{Alcohol Manipulation Check}

To assess comprehension of the intoxication manipulation, participants reported the victim's intoxication level via a multiple-choice question. Response options reflected all levels included in the study, plus a 'don't know' option to minimise guessing.

\section{Influences on Decision-Making}

To test the efficacy of primary manipulations, participants rated the impact of several factors on their decision-making via a 7 -point Likert scale $(1=$ no influence, $7=$ extremely influential). Higher scores indicate greater influence.

\section{Alcohol Consumption}

Personal alcohol consumption was assessed using the Alcohol Use Disorders Identification Test - Consumption (AUDIT-C; Bush et al., 1998); a three-item screening tool for hazardous alcohol use. The AUDIT-C is scored on a scale of 0 to 12 points, and higher scores indicate greater consumption.

\section{Alcohol Familiarity}

Alcohol familiarity was measured using four items adapted from Monds et al. (2021). Participants reported how often they witnessed others drinking and intoxicated by alcohol. Responses were given on a 6-point Likert scale $(1=$ never, $6=$ daily $)$, where higher scores indicate greater regularity. The third item asked if participants had witnessed an alcoholrelated crime. Responses were provided on a binary yes/no scale. Those who answered 'yes' were asked to describe the nature of the crime.

\section{Alcohol Accreditation and Work Experiences}

Two items adapted from Monds et al. (2021) asked whether participants had worked in a role involving alcohol service, and if they had completed training or an accreditation for this purpose. Responses were delivered on a binary yes/no scale. Those with an affirmative 
response to the second item were asked to provide the name of the accreditation and the country it was completed in.

\section{Attention Checks}

Attention check questions (e.g., 'Select disagree here') were incorporated into the ASI, POPS, perceived credibility, and influences on decision-making scales. Incorrect answers determined exclusion based on failure to pay adequate attention to the study.

\section{Procedure}

Participants provided informed consent and then completed the demographic questionnaire. Drinking beliefs were assessed, then participants responded to the ASI and POPS. They were then randomly assigned to read one of eight trial transcripts. After reviewing the case material, participants delivered a dichotomous verdict and reported the likelihood that the defendant committed the crime. They then rated the responsibility of the victim and perpetrator, and the credibility of the victim as a witness. Comprehension of the alcohol manipulation was assessed, then participants rated the influence of several factors on their decision-making. The study concluded with questions about alcohol consumption, familiarity, and work/training experiences.

\section{Results}

\section{Sample Characteristics}

Participants who spent less than thirty seconds reading each transcript page, failed an attention check, or were under eighteen years of age were excluded from analyses $(n=105)$. A further $29.8 \%$ of participants were unable to correctly recall the victim's intoxication status. Cullen and Monds (2020) advise against excluding mock jurors based on poor memory, as real jurors often cannot recall trial information. These participants therefore remained in the analyses to benefit ecological validity. 
The final sample consisted of 228 participants ( 157 female, 70 male, 1 non-binary). The average age was 20.46 years $(S D=3.32$, ranging from 18 to 45 years) and $53.5 \%$ of participants were Australian citizens. Participants were predominantly of Asian (54.4\%) and Australian (25.0\%) ethnicity. In total, $15.8 \%$ of participants had worked in a role involving alcohol service and $21.5 \%$ possessed an alcohol accreditation. Among those who had witnessed an alcohol-related crime, physical assault was the most reported (50.0\%). Participants most often witnessed others drinking alcohol weekly (35.5\%) and intoxicated by alcohol yearly $(25.4 \%)$.

\section{Primary Analyses}

\section{Perceived Victim Credibility}

Mock jurors' perceptions of victim credibility were measured via a seven-item scale, and item responses were added to provide a total victim credibility score. As expected, a 4 (victim intoxication status) x 2 (crime type) between subjects ANOVA yielded a significant main effect of victim intoxication status on perceived credibility, $F(3,220)=7.59, p<.001$. Surprisingly, neither a significant main effect of crime type nor an interaction with victim intoxication status was observed, both $p \geq .401$.

To further explore the significant effect of victim intoxication status, planned contrasts were conducted using the Bonferroni method. Averaged across crime type, sober victims $(M=38.25)$ were perceived as significantly more credible than intoxicated victims $(M=33.80), F(1,220)=17.36, p<.001$. No other contrasts were significant, both $p \geq .069$.

\section{Dichotomous Verdicts}

In total, $79.8 \%$ of mock jurors convicted the defendant, while $20.2 \%$ delivered a not guilty verdict. Contrary to hypotheses, chi-square analyses indicated that neither victim intoxication status nor crime type were significantly associated with dichotomous verdict, both $p \geq .076$. However, a significant relationship emerged when these variables were 
considered together. Mock jurors' distribution across verdict options was significantly related to intoxication status in the robbery condition, $\chi^{2}(3, N=228)=9.43, p=.024$, but not in the rape condition, $p=.778$. Post-hoc $z$-tests with the Bonferroni adjustment indicated that the proportion of mock jurors in the robbery condition rendering each verdict type differed significantly only when the victim was sober or moderately intoxicated, both $p<.05$.

\section{Verdict Ratings}

Due to low cell counts, the 7-point verdict rating scale was collapsed into three broader categories: lower probability of guilty $(1-3)$, neutral (4), and higher probability of guilt (5-7). Surprisingly, chi-square analyses revealed that the relationships between verdict rating and both independent variables failed to reach significance, both $p \geq .988$. No significant differences were observed when the association between verdict rating and intoxication status was considered in either rape or robbery cases specifically, both $p \geq .065$.

\section{Perceived Victim and Defendant Responsibility}

Contrary to hypotheses, chi-square analyses demonstrated that neither the association between perceptions of victim responsibility and intoxication status nor crime type were significant, both $p \geq .186$. This unexpected pattern of results was replicated when the relationships between defendant responsibility and independent variables were tested, both $p$ $\geq .201$. As mock jurors' perceptions of victim credibility and verdicts - rather than judgements of responsibility - are the primary focus of this study, these variables will not be explored further.

\section{Secondary Analyses}

\section{Rationale}

A secondary aim of the present study was to assess the robustness of primary analyses within a more well-rounded picture of jury decision-making. Therefore, the contribution of relevant extra-legal factors was explored alongside victim intoxication status and crime type. 
Personal alcohol consumption, drinking beliefs, and sexist attitudes towards women were included in all subsequent analyses. Demographic factors that yielded significant sample differences among outcome variables were also included.

Alcohol consumption scores ranged from 0 to $12(M=3.02, S D=2.19)$. Those who failed to answer all AUDIT-C items were excluded from analyses $(n=49)$. Therefore, all subsequent analyses were performed on a sample of 179 participants. Two sexism scores were generated per participant: a total hostile sexism score and a total benevolent sexism score. The average HS score was $14.89(S D=5.56)$ and the average BS score was 15.39 (SD $=5.81)$. Finally, all five drinking belief items were collapsed across response categories to manage low cell counts.

\section{Perceived Victim Credibility}

A linear regression assessed the influence of victim intoxication status and crime type on perceived credibility alongside extra-legal factors. Since preliminary analyses revealed significant differences in credibility according to ethnicity, it was included in the regression.

Controlling for all variables, victim intoxication status, hostile sexism, and the comparison between Asian and Australian participants significantly predicted victim credibility. The victim was considered less credible by 4.21 units when she was intoxicated compared to sober, $\beta=-0.246, t(176)=-3.57, p<.001$. A one-point increase in hostile sexism was accompanied by a 0.33 unit decrease in credibility rating, $\beta=-0.246, t(176)=-$ $2.42, p=.017$. Finally, Asian participants rated the victim as less credible by 3.31 units compared to Australian participants, $\beta=-0.225, t(176)=-2.42, p=.017$. No other predictors were significant, all $p \geq .106$. 


\section{Dichotomous Verdicts}

A binary logistic regression investigated the influence of victim intoxication status, crime type, and extra-legal factors on dichotomous verdicts. Gender and ethnicity were also included given significant preliminary analyses. ${ }^{1}$

Controlling for all other variables, gender, ethnicity, and the belief that alcohol negatively impacts memory significantly predicted dichotomous verdicts. More specifically, females were 0.26 times more likely to acquit the defendant compared to males, $b=-1.342, p$ $=.002$. Furthermore, Asian mock jurors were 0.34 times less likely to return a not guilty verdict compared to Australians, $b=-1.082, p=.041$. It must be noted that the significance of the comparison between Asian and Australian participants was reduced when drinking beliefs were added to the model, $p=.050$.

A chi-square test performed on the significant drinking belief revealed that the proportion of mock jurors delivering guilty and not guilty verdicts differed significantly according to the extent that mock jurors believed that alcohol impairs memory, $\chi^{2}(2, N=$ $228)=7.04, p=.030$. Post-hoc $z$-tests with the Bonferroni adjustment indicated that this significant difference was present only among those who perceived the impairment to be nonexistent/marginal, $p<.05$.

\footnotetext{
${ }^{1}$ The ordinal drinking belief items were entered hierarchically to obtain meaningful interpretations rather than arbitrary dummy-coded comparisons of within-item response categories (as is the fixed option in SPSS). The predictive power of each drinking belief item was then derived by comparing the chi-square value of the most recent model to its predecessor (Rodríguez, 2007).
} 


\section{Verdict Ratings}

A series of ordinal logistic regressions explored the effect of crime type, victim intoxication status, and extra-legal factors on verdict ratings. As verdict ratings were not significantly influenced by demographic variables, none were included in the regression. ${ }^{2}$

Only the belief that intoxicated victims are somewhat responsible for their victimisation was significantly associated with verdict ratings, $\chi^{2}=11.51, p<.05$. An additional chi-square test revealed that the proportion of mock jurors in each rating category differed significantly according to endorsement of this belief, $\chi^{2}(4, N=228)=10.93, p=$ .027. Post-hoc $z$-tests using the Bonferroni adjustment indicated that the difference was significant only among those who either disagreed or expressed a neutral opinion, both $p<$ .05 .

\section{Discussion}

As predicted, the victim's intoxication status significantly influenced mock jurors' perceptions of her credibility. However, mock jurors did not discriminate between alcohol doses when making this assessment, and victim intoxication status failed to significantly influence trial verdicts. Contrary to hypotheses, crime type did not significantly impact mock jurors' assessments of credibility or verdict decisions.

The study also investigated whether these variables maintained their role in jury decision-making when extra-legal factors were also considered. While victim intoxication status retained its significant impact on credibility, this was also significantly influenced by mock jurors' ethnicity and hostile sexism. Finally, gender, ethnicity, and drinking beliefs predicted mock jurors' verdicts over and above victim intoxication status and crime type.

\footnotetext{
${ }^{2}$ To obtain meaningful interpretations of the effect of ordinal drinking belief variables, these items were gradually included in a sequence of regressions. The contribution of each belief was then assessed by comparing the deviance test statistic of each model and its predecessor (Rodríguez, 2007).
} 


\section{Victim Intoxication Status}

\section{Assessment in a Legal Setting}

Consistent with previous research, mock jurors perceived alcohol as detrimental to memory (e.g., Benton et al., 2006; Monds et al., 2021). However, they failed to distinguish between different levels of intoxication when making this judgement. This result builds upon the findings of Evans and Schreiber Compo (2010): just the presence of alcohol - even at a low level - can discredit a victim's testimony.

Evans and Schreiber Compo (2010) accounted for the dosage-blind effect by highlighting the contribution of the legal setting. Trial decision-making has serious consequences, and the principle of reasonable doubt sets a high standard for evidence. Mock jurors may have been cautious when assessing the victim's impairment, especially at lower levels of intoxication when the degree of impairment is less clear. Their subsequent conservative evaluation of testimony may have collapsed the intoxication spectrum into a simple sober vs. intoxicated binary, erasing differential effects across doses.

\section{Inconsistent Evaluations of Victim Intoxication}

Alternatively, the dosage-blind effects may be the product of a discrepancy conscious or otherwise - between mock jurors' judgements of the victim's intoxication level and her self-assessment. This explanation is supported by the proportion of participants who failed the alcohol manipulation check: nearly a third of the sample incorrectly reported the victim's intoxication status. This may be due to recall error but could also be the product of such a discrepancy.

Assessment of intoxication varies significantly with blood alcohol concentration, highlighting considerable diversity in how people map drunkenness on to objective levels of intoxication (Rossheim et al., 2016). Thus, mock jurors' varied evaluation of intoxication indicators (e.g., number of drinks) may have produced discordance with the victim's self- 
assessment. Alternatively, even 'experts' such as police and medical professionals are extremely ineffective at judging the intoxication status of others (Rubenzer, 2011). Therefore, jurors likely could not reliably identify intoxication status based on alcohol-related cues.

Together these explanations suggest that inconsistent evaluations of the victim's intoxication status prohibited dose-specific findings. Further research must distinguish between participants' interpretation of the victim's intoxication level and memory of her selfdisclosure to validate this conclusion.

\section{Perceptions of Victim Credibility and Verdicts}

Although alcohol interferes with memory only after significant consumption, the current study suggests that jurors believe alcohol is detrimental to memory at any dose (Jores et al., (2019). Accordingly, it appears that jurors possess erroneous beliefs about the effects of intoxication on eyewitness memory and testimony. However, these erroneous beliefs did not influence trial verdicts. This finding aligns with research suggesting that jurors struggle to integrate abstract knowledge and beliefs about eyewitness testimony into formal decisionmaking (Alonzo \& Lane, 2010). That is, jurors' knowledge does not always predict their decisions, even when highly relevant. Additional explanations for the null verdict effects are explored below.

\section{Crime Type}

\section{Consistency Across Crime Scenarios}

Contrary to hypotheses, crime type did not significantly influence mock jurors' perceptions of victim credibility or verdicts. These findings deviate from previous research suggesting that jurors reach more pro-defence decisions in rape trials compared to robbery trials (Bieneck \& Krahé, 2011; Spille, 2015). This deviation is likely due to the inconsistencies between crime scenarios used in these previous studies: the rape took place at 
night in a carpark and the victim was not threatened with weapons; the robbery took place during the day outside a bank, and the victim was threatened with a knife and a large dog.

Given these inconsistencies, the present study reviewed the validity of previous findings by improving experimental control. Crime conditions were identical beyond key manipulations and therefore the current non-significant results cast doubt over previous findings. They appear to be due to extraneous details (e.g., the inconsistent presence of a weapon) rather than genuine crime type effects. Future research must use new scenarios to test the credibility of this conclusion and obtain more robust results.

\section{Type of Rape}

The lack of crime type differences may also be a product of the stranger rape scenario used. Stranger rape provided the best way to replicate and authenticate previous findings by ensuring situational consistency with robbery. However, victims of acquaintance rape are blamed significantly more than victims of stranger rape (Abrams et al., 2003).

The real rape stereotype accounts for this attributional variation. It inaccurately describes a typical rape as an abrupt, public attack by a stranger. This is problematic because it is prescriptive: by identifying the features of an archetypal rape, the stereotype informs whether a victim is perceived as genuine (Temkin \& Krahé, 2008). Mock jury deliberation research suggests that this ill-informed stereotype can shape jury decision-making, leading to more pro-defence decisions (Leverick, 2020). As the stranger rape in the current study largely conformed to the real rape stereotype, it is possible that derogation of the rape victim was minimised because the assault was more readily perceived as genuine. This requires exploration in future research.

\section{The Interaction Between Victim Intoxication Status and Crime Type}

Surprisingly, victim intoxication status and crime type did not interact to inform perceptions of victim credibility or verdict ratings. These non-significant findings are likely 
the result of previously outlined issues with precise interpretation of intoxication levels, and the absence of crime type effects. Meaningful conclusions about the interaction therefore cannot be made until the impact of experimental design on null findings is established.

The interaction between victim intoxication status and crime type in the context of dichotomous verdicts must be noted. Significant differences in the proportion of guilty and not guilty verdicts were observed only when the robbery victim was sober or moderately intoxicated. As this result lacks a theoretical basis, future research should strive for replication before interpretation.

\section{The Role of Extra-Legal Factors}

\section{Hostile Sexism}

Mock jurors with higher levels of hostile sexism viewed the victim as less credible. Hostile sexism reliably predicts victim blaming in sexual assault cases (Sakallı-Uğurlu et al., 2010). However, the consistent lack of crime type difference in the present study suggests that hostile sexism promotes the derogation of female victims beyond rape. Hostile sexism promotes a conceptualisation of women as ostensibly manipulative, dishonest, and overly emotional (Glick \& Fiske, 1996). Endorsement of these beliefs therefore may encourage a general tendency to disbelieve a woman who claims she was victimised by a man. Future research is required to validate this conclusion and further define the relationship between hostile sexism and victim derogation across a variety of crimes.

\section{Drinking Beliefs}

Differences in the proportion of mock jurors favouring conviction compared to acquittal were observed among those who believed that (1) the negative impact of alcohol on memory is non-existent or marginal, and (2) intoxicated victims are somewhat responsible for their victimisation. It is difficult to establish the genuine influence of these drinking beliefs when they are interpreted against the existing literature. Evans and Schreiber Compo (2010) 
failed to document a relationship between drinking beliefs and mock jurors' judgements, while Crossland et al. (2021) observed a significant association only when the victim was moderately intoxicated. Alternatively, Zhu et al. (2021) found that drinking beliefs predicted mock jurors' decision-making even when the victim was sober.

Drinking beliefs are yet to occupy the primary focus of a study exploring intoxicationrelated jury decision-making. Future research must measure these beliefs more comprehensively to clarify their consequences for jurors' judgements, including differential effects across alcohol expectancy domains (e.g., memory vs. decision-making).

\section{Limitations and Future Directions}

Like most jury deliberation research conducted with an undergraduate sample, several caveats apply to the current study. Most participants were aged between 18 - 20 years and female. However, meta-analytic research asserts that student samples do not necessarily damage the generalisability of jury simulation studies (Bornstein et al., 2017). Moreover, Powers et al. (2015) observed few discrepancies in alcohol expectancies among university and community samples. Limited generalisability therefore does not appear to be a significant issue - but replication with a more diverse, representative sample would strengthen conclusions.

The study lacked a deliberation stage, which may have corrected erroneous beliefs about alcohol and its relationship with victimhood. A brief transcript was used to maintain experimental control and participant engagement, but its modality and length differed from a real trial. Thus, replication with a more extended, ecologically valid simulation (e.g., a videotaped trial with group deliberation) would reinforce interpretations.

\section{Conclusion}

Jurors evidently do not understand how alcohol affects eyewitness memory. While jurors' misconceptions ultimately did not impact verdict decisions, a lack of dose-specificity 
when judging victim credibility asserts the need for jury education. At the very least, the assumption that the relationship between alcohol and memory is common knowledge must be displaced from legal practice. The introduction of expert witnesses and evidence-based judicial instructions represent initial steps towards this goal (Nitschke et al., 2021).

Unfortunately, conclusions about the effect of crime type on jury decision-making and its interaction with victim intoxication status - cannot yet be made. Instead, the current study stresses that the existing crime type literature is hindered by methodological issues that must be resolved. This resolution is important. Rapes are seldom reported to police, rarely proceed to trial, and even less frequently end in conviction (Heath, 2007). Thus, research that can minimise the procedural vulnerabilities of rape victims is essential.

The importance of extra-legal factors must also be recognised. This study explored only a handful of these factors, but it is clear that the scope of intoxication-related jury research must widen. It is not enough to investigate the features of an intoxication-related crime, as extra-legal factors shape the way these crimes are adjudicated. Future research therefore has the potential to benefit voir dire strategies.

Together these conclusions set the agenda for a comprehensive program of future research. Jurors tend towards flawed assessment of intoxication-related testimony, and therefore additional research is essential to preserve the integrity of legal proceedings in these cases. 


\section{References}

Abrams, D., Viki, G. T., Masser, B., \& Bohner, G. (2003). Perceptions of stranger and acquaintance rape: The role of benevolent and hostile sexism in victim blame and rape proclivity. Journal of Personality and Social Psychology, 84(1), 111 - 125. https://doi.org/10.1037/0022-3514.84.1.111

Alonzo, J. D., \& Lane, S. M. (2010). Saying versus judging: Assessing knowledge of eyewitness memory. Applied Cognitive Psychology, 24(9), 1245 - 1264. https://doi.org/10.1002/acp.1626

Altman, C. M., Schreiber Compo, N., McQuinston, D., Hagsand, A. V., \& Cervera, J. (2018). Witness' memory for events and faces under elevated levels of intoxication. Memory, 26(7), 946 - 959. https://doi.org/10.1080/09658211.2018.1445758

Benton, T. R., Ross, D. F., Bradshaw, E., Thomas, W. N., \& Bradshaw, G. S. (2006). Eyewitness memory is still not common sense: Comparing jurors, judges, and law enforcement to eyewitness experts. Applied Cognitive Psychology, 20(1), 115 - 129. https://doi.org/10.1002/acp.1171

Berman, G. L., \& Cutler, B. L. (1996). Effects of inconsistencies in eyewitness testimony on mock juror decision-making. Journal of Applied Psychology, 81(2), 170 - 177. https://doi.org/10.1037/0021-9010.81.2.170

Bieneck, S., \& Krahé, B. (2011). Blaming the victim and exonerating the perpetrator in cases of rape and robbery: Is there a double standard? Journal of Interpersonal Violence, 26(9), 1785 - 1797. https://doi.org/10.1177/0886260510372945

Blume, S. (1986). Women and alcohol. A review. JAMA, 156(11), 1467 - 1470. https://doi.org/10.1001/jama.1986.03380110073029 
Bogren, A. (2008). Women's intoxication as 'dual licentiousness': An exploration of gendered images of drinking and intoxication in Sweden. Addiction Research \& Theory, 16(1), 95 - 106. https://doi.org/10.1080/16066350701668895

Bornstein, B. H., Golding, J. M., Neuschatz, J., Kimbrough, C., Reed, K., Magyarics, C., \& Leucht, K. (2017). Mock juror sampling issues in jury simulation research: A metaanalysis. Law and Human Behaviour, 41(1), 13 - 28. https://doi.org/10.1037/lhb0000223

Burt, M. R. (1980). Cultural myths and supports for rape. Journal of Personality and Social Psychology, 38(2), 217 - 230. https://doi.org/10.1037/0022-3514.38.2.217

Bush, K., Kivlahan, D. R., McDonell, M. B., Fihn, S. D., \& Bradley, K. A. (1998). The AUDIT Alcohol Consumption Questions (AUDIT-C): An effective brief screening test for problem drinking. Archives of Internal Medicine, 158(16), 1789-1795. https://doi.org/10.1001/archinte.158.16.1789

Crossland, D., Kneller, W., \& Wilcock, R. (2021). Mock juror perceptions of intoxicated witness credibility. Journal of Police and Criminal Psychology. Advance online publication. https://doi.org/10.1007/s11896-021-09430-5

Cullen, H. J., \& Monds, L. A. (2020). Jury simulation studies: To exclude or not to exclude based on a lack of comprehension of the case? Applied Cognitive Psychology, 34(5), 1224 - 1233. https://doi.org/10.1002/acp.3695

Cullen, H. J., Paterson, H. M., \& van Golde, C. (2020). Mock juror perceptions of witness inattentional blindness. Journal of Police and Criminal Psychology. Advance online publication. https://doi.org/10.1007/s11896-020-09399-7

Evans, J. R., \& Schreiber Compo, N. (2010). Mock jurors' perceptions of identifications made by intoxicated eyewitnesses. Psychology, Crime \& Law, 16(3), $191-210$. https://doi.org/10.1080/10683160802612890 
Fejervary, J. (2017). Words matter: Measuring rape myth acceptance through survey design [Master's thesis, Northern Arizona University]. CORE. https://core.ac.uk/download/pdf/151423147.pdf

Felson, R. B., \& Palmore, C. C. (2021). Traditionalism and victim blaming. The Journal of Social Psychology. Advance online publication. https://doi.org/10.1080/00224545.2021.1896466

Finch, E., \& Munro, V. E. (2007). The demon drink and the demonised woman: Socio-sexual stereotypes and responsibility attribution in rape trials involving intoxicants. Social \& Legal Studies, 16(4), 591 - 614. https://doi.org/10.1177/0964663907082737

Flowe, H. D., Colloff, M. F., Kloft, L., Jores, T., Stevens, L. M. (2019). Impact of alcohol and other drugs on eyewitness memory. In R. Bull \& I. Blandón-Gitlin (Eds.), The Routledge international handbook of legal and investigative psychology (pp. 149 162). Routledge.

Glick, P., \& Fiske, S. T. (1996). The ambivalent sexism inventory: Differentiating hostile and benevolent sexism. Journal of Personality and Social Psychology, 70(3), 491 - 512. https://doi.org/10.1037/0022-3514.70.3.491

Glick, P., \& Whitehead, J. (2010). Hostility toward men and the perceived stability of male dominance. Social Psychology, 41(1), 177 - 185. http://doi.org/10.1027/18649335/a000025.

Heath, M. (2007). Lack of conviction: A proposal to make rape illegal in South Australia. Australian Feminist Law Journal, 27(1), 175 - 192. https://doi.org/10.1080/13200968.2007.10854391

Holst, V. F., \& Pezdek, K. (1992). Scripts for typical crimes and their effects on memory for eyewitness testimony. Applied Cognitive Psychology, 6(7), 573 - 587. https://doi.org/10.1002/acp.2350060702 
Horan, J., \& Goodman-Delahunty, J. (2010). Challenging the peremptory challenge system in Australia. Criminal Law Journal, 34(3), 2010. University of Melbourne Legal Studies Research Paper. https://ssrn.com/abstract=2439524

Jores, T., Colloff, M. F., Kloft, L., Smailes, H., \& Flowe, H. D. (2019). A meta-analysis of the effects of acute alcohol intoxication on witness recall. Applied Cognitive Psychology, 33(3), 334 - 343. https://doi.org/10.1002/acp.3533

Judicial Commission of New South Wales. (2021). Criminal Trial Courts Bench Book. https://www.judcom.nsw.gov.au/criminal/

Kloft, L., Monds, L. A., Blokland, A., Ramaekers, J. G., \& Otgaar, H. (2021). Hazy memories in the courtroom: A review of alcohol and other drug effects on false memory and suggestibility. Neuroscience \& Biobehavioural Reviews, 124(1), 291 307. https://doi.org/10.1016/j.neubiorev.2021.02.012

Leverick, F. (2020). What do we know about rape myths and juror decision making? The International Journal of Evidence and Proof, 24(3), 255 - 279. https://doi.org/10.1177/1365712720923157

Lynch, K. R., Wasarhaley, N. E., Golding, J. M., \& Simcic, T. (2013). Who bought the drinks? Juror perceptions of intoxication in a rape trial. Journal of Interpersonal Violence, 28(16), 3205 - 3222. https://doi.org/10.1177/0886260513496900

McMahon, S., \& Farmer, G. L. (2011). An updated measure for assessing subtle rape myths. Social Work Research, 35(2), 71 - 81. $\underline{\text { https://doi.org/10.1093/swr/35.2.71 }}$

Monds, L. A., Cullen, H. J., Kloft, L., van Golde, C., Harrison, A. W., \& Flowe, H. (2021). Memory and credibility perceptions of alcohol and other drug intoxicated witnesses and victims of crime. Psychology, Crime \& Law. Advance online publication. https://doi.org/10.1080/1068316X.2021.1962871 
Nadal, K. L., \& Davidoff, K. C. (2015). Perceptions of police scale (POPS): Measuring attitudes towards law enforcement and beliefs About police bias. Journal of Psychology and Behavioural Science, 3(2), 1 - 9. http://ds.doi.org/10.15640/jpbs.v3nza1

National Road Safety Partnership Program. (2017). Am I right to drive? Understanding how drinking affects your BAC 'the morning after'. https://www.nrspp.org.au/2017/09/21/right-drive-understanding-drinking-affects-bacmorning/

Nitschke, F. T., Masser, B. M., McKimmie, B. M., \& Riachi, M. (2021). Intoxicated but not incapacitated: Are there effective methods to assist juries in interpreting evidence of voluntary complainant intoxication in cases of rape? Journal of Interpersonal Violence, $36(9$ - 10), 4335 - 4359. https://doi.org/10.1177/0886260518790601

O’Dell, L., Crafter, S., de Abreu, G., \& Cline, T. (2012). The problem of interpretation in vignette methodology research with young people. Qualitative Research 12(6), 702 714. https://doi.org/10.1177/1468794112439003

Powers, R. A., Leili, J., Hagman, B., \& Cohn, A. (2015). The impact of college education on rape myth acceptance, alcohol expectancies, and bystander attitudes. Deviant Behaviour, 26(12), 956 - 973. https://doi.org/10.1080/01639625.2014.982747

Quilter, J., \& McNamara, L. (2018). The meaning of “intoxication” in Australian criminal cases: Origins and operation. New Criminal Law Review, 21(1), 170 - 207. https://doi.org/10.1525/nclr.2018.21.1.170

Rodríguez, D. J. (2007). Lecture notes on generalised linear models. https://data.princeton.edu/wws509/notes/

Rossheim, M. E., Thombs, D. L., Gonzalez-Pons, K. M., Killion, J. A., Clapp, J. D., Reed, M. B., Croff, J. M., Ruderman, D. E., \& Weiler, R. M. (2016). Feeling no buzz or a slight 
buzz is common when legally drunk. American Journal of Public Health, 106(10), 1761 - 1762. https://doi.org/10.2105/AJPH.2016.303321

Rubenzer, S. (2011). Judging intoxication. Behavioural Sciences and the Law, 29(1), 116 137. https://doi.org/10.1002/bs1.935

Sakall1-Uğurlu, N., Salman, S., \& Turgut, Sinem. (2010). Predictors of Turkish women's and men's attitudes toward sexual harassment: Ambivalent sexism, and ambivalence toward men. Sex Roles, 63(11), 871 - 881. https://doi.org/10.1007/s11199-010-9847-6

Schuller, R. A., \& Wall, A. M. (2006). The effects of defendant and complainant intoxication on mock jurors' judgements of sexual assault. Psychology of Women Quarterly, 22(4), 555 - 573. https://doi.org/10.1111/j.1471-6402.1998.tb00177.x

Spille, L. (2015). Deciding who to blame for rape and robbery in Turkey: Perpetrators' coercive strategy, victim-perpetrator relationship, participant gender, and rape myth acceptance [Master's thesis, University of Potsdam]. University of Potsdam. https://doi.org/10.25932/publishup-42327

Suarez, E., \& Gadalla, T. M. (2010). Stop blaming the victim: A meta-analysis on rape myths. Journal of Interpersonal Violence, 25(11), 2010 - 2035. https://doi.org/10.1177/0886260509354503

Temkin, J., \& Krahé, B. (2008). Sexual assault and the justice gap: A question of attitude. Hart Publishing.

Zhu, L., Cullen, H. J., Hunt, C. J., \& Monds, L. A. (2022). The influence of victim intoxication and inconsistent testimony on mock juror decision making. Manuscript submitted for publication. 